\title{
Desempenho reprodutivo e zootécnico e deposição de lipídios nos hepatócitos de fêmeas de tilápia-do-nilo alimentadas com rações de diversos níveis energéticos
}

\author{
Robie Allan Bombardelli ${ }^{1}$, Carmino Hayashi², Maria Raquel Marçal Natali ${ }^{3}$, Eduardo Antônio \\ Sanches ${ }^{4}$, Pitágoras Augusto Piana ${ }^{5}$
}

\footnotetext{
${ }^{1}$ Curso de Engenharia de Pesca - Universidade Estadual do Oeste do Paraná

2 Universidade Estadual de Maringá.

${ }^{3}$ Departamento de Ciências Morfofisiológicas - Universidade Estadual de Maringá.

${ }^{4}$ Mestrando do Curso de Aqüicultura - Universidade Estadual Paulista.

${ }^{5}$ Curso de Engenharia de Pesca - Universidade Estadual do Oeste do Paraná.
}

\begin{abstract}
RESUMO - Um experimento foi conduzido com o objetivo de avaliar os desempenhos reprodutivo e zootécnico e a deposição de lipídios no tecido hepático de fêmeas de tilápia-do-nilo alimentadas com rações contendo diferentes níveis de energia digestível, obtidos pela inclusão de óleo de soja. Foram utilizados 100 reprodutores e 300 reprodutoras, distribuídos em delineamento inteiramente casualizado com cinco tratamentos e quatro repetições. Os reprodutores, machos e fêmeas, foram alimentados com rações contendo, por quilograma, 35\% de proteína bruta e 2.700, 2.950, 3.200, 3.450 ou $3.700 \mathrm{kcal}$ de energia digestível. Os animais foram mantidos em hapas por 93 dias. O desempenho reprodutivo e zootécnico não foi influenciado pelos níveis energéticos das rações, o que pode estar relacionado ao curto período de tempo de alimentação com as dietas experimentais. Contudo, o aumento nos níveis de energia teve efeito linear nas deposições lipídicas nos hepatócitos Desta forma, os níveis crescentes de energia digestível nas rações fornecidas às fêmeas de tilápia-do-nilo, obtidos pela inclusão de óleo de soja, apenas aumentam o tempo de sobrevivência das larvas ao jejum e a deposição de lipídios nos hepatócitos das fêmeas.
\end{abstract}

Palavras-chave: fígado, nutrição, Oreochromis niloticus, ovários, peixe, reprodução

\section{Reproductive and animal performance and lipids deposition in hepatocytes for Nile tilapia females fed different levels of energy in the ration}

\begin{abstract}
The experiment was carried out to evaluate the reproductive and animal performance and lipids deposition in the liver tissue of the Nile tilapia female, fed diets containing different levels of digestible energy, obtained by soybean oil inclusion. Three hundred breeding females and 100 breeding males were used, distributed in a completely randomized design with five treatments and four replications. The broods were fed diets containing $35 \%$ crude protein and 2,700; 2,950;3,200; 3,450 and 3,700 kcal energy digestible/kg feed. The animals were stocked in hapas for 93 days. The reproductive and animal performance were not influenced by the energy levels. These results may be associated with the short period of time that the brood were fed the experimental diets. However, increasing energy levels caused a linear increase in lipids inclusions in hepatocytes. Thus, the increasing levels of digestible energy provided to Nile tilapia females, obtained by including soybean oil, only promoted increased lipid deposition in hepatocytes.
\end{abstract}

Key Words: fish, liver, nutrition, Oreochromis niloticus, ovaries, reproduction

\section{Introdução}

A tilapicultura agrega o segundo maior grupo de peixes de água doce criados (Alceste \& Jorry, 1998) e é uma das atividades agropecuárias de maior crescimento no mundo (Wing-Keong, 2002). No Brasil, em 2000 e 2001, a tilapicultura seguiu a mesma tendência mundial (Borghetti et al., 2003), uma vez que a tilápia foi a principal espécie produzida nos anos de 2002, 2003 (Crescêncio, 2005) e 2005 (IBAMA, 2007).

Para atender ao crescimento da tilapicultura, é fundamental o fornecimento contínuo de ovos, larvas e juvenis, em quantidade e qualidade (Watanabe, 1985; Little et al., 1997), por isso, é importante a realização de estudos voltados à nutrição (Watanabe et al., 2002), à alimentação e ao manejo de reprodutores (Bromage, 1995; Hardy, 1999). 
A nutrição merece especial atenção por afetar diretamente o funcionamento e a morfologia do fígado, importante no metabolismo e fornecimento de energia (Caballero et al., 2004). Além disso, aspectos nutricionais podem ter implicações no desempenho reprodutivo (Watanabe \& VassaloAgius, 2003) e na larvicultura (Izquierdo et al., 2001) de peixes.

Informações sobre nutrição de tilápias em fase de crescimento são abundantes (Santiago \& Laron, 2002), contudo, há poucos estudos sobre nutrição de reprodutores devido, principalmente às dificuldades experimentais (Brooks, et al., 1997; Vassalo-Agius et al., 2001). Entre os estudos constantes na literatura, alguns incluem a avaliação dos efeitos da inclusão de proteína dietética sobre o desempenho reprodutivo de fêmeas (Gunasekera et al., 1995; Gunasekera \& Lam, 1997; Al-Hafedh et al., 1999) e a qualidade da prole (Gunasekera et al., 1996; Gunasekera et al., 1997).

Outros nutrientes, como os lipídios, têm sido estudados para reprodutores de várias espécies de peixes (Bell et al., 1997; Almansa et al., 1999; Asturiano et al., 2001), tendo em vista sua importância como fonte de energia metabólica (Tyler \& Sumpter, 1996) e de ácidos graxos essenciais para a atividade fisiológica dos reprodutores e para as proles (Sargent et al., 1999; Mazorra et al., 2003), no entanto, são escassas as informações quanto às exigências energéticas para reprodutores de tilápia (Bhujel, 2000).

Este trabalho foi conduzido com o objetivo de avaliar os desempenhos reprodutivo e zootécnico e a deposição de lipídios no tecido hepático de fêmeas de tilápia-do-nilo (Oreochromis niloticus L.) alimentadas com rações contendo diferentes níveis de energia digestível, obtidos pela inclusão de óleo de soja.

\section{Material e Métodos}

O experimento foi realizado durante o período de 11 de janeiro a 15 de abril de 2005, no Laboratório de Tecnologia da Reprodução dos Animais Aquáticos Cultiváveis da Universidade Estadual do Oeste do Paraná (UNIOESTE), no Centro de Pesquisa em Aquicultura Ambiental (CPAA) do Instituto Ambiental do Paraná, por meio do convênio IAP/UNIOESTE, e no Laboratório de Histotécnica Animal do Departamento de Ciências Morfofisiológicas da Universidade Estadual de Maringá, Paraná.

Foram utilizados 400 reprodutores de tilápia-do-nilo (Oreochromis niloticus), linhagem Tai - Chitralada: 300 fêmeas $(112,82 \pm 3,23 \mathrm{~g})$ e 100 machos $(146,06 \pm 3,43 \mathrm{~g})$. Os reprodutores foram alojados separadamente em 40 hapas (malha $1 \mathrm{~mm} \times 4 \mathrm{~mm}$ ) distribuídas aleatoriamente em dois viveiros escavados $(20 \mathrm{~m} \times 10 \mathrm{~m})$.
As fêmeas foram estocadas em 20 hapas de dimensões $3 \mathrm{~m} \times 2 \mathrm{~m}$, na densidade de 2,5 animais $/ \mathrm{m}^{2}$, totalizando 15 fêmas por hapa. Os machos foram estocados em 20 hapas de dimensões $2 \mathrm{~m} \times 1 \mathrm{~m}$, na densidade de 2,5 animais $/ \mathrm{m}^{2}$, totalizando cinco machos por hapa. Foi considerado unidade experimental um hapa de $3 \mathrm{~m} \times 2 \mathrm{~m}$ contendo 15 fêmeas e cinco machos em acasalamento. Esse procedimento foi adotado visando respeitar a proporção entre os sexos, de um macho para três fêmeas (Little \& Hulata, 2000; El-Sayed et al., 2005).

Os animais foram distribuídos em delineamento experimental inteiramente casualizado, composto de cinco tratamentos, cada um com quatro repetições. Avaliaram-se cinco rações contendo $35 \%$ de proteína bruta (Bhujel et al., 2001) e cinco níveis de energia digestível $(2.700 ; 2.950 ; 3.200 ; 3.450$ e $3.700 \mathrm{kcal} / \mathrm{kg}$ de ração). O aumento do nível energético das rações foi obtido com a inclusão de óleo de soja. Os reprodutores de ambos os sexos foram alimentados com rações formuladas (Tabela 1) e processadas na forma peletizada, com péletes de $2 \mathrm{~mm}$ de diâmetro. Para elaboração das rações, os ingredientes foram triturados em moinho de martelo com peneira de 0,5 mm (Hayashi et al., 1999; Meurer et al., 2005).

Tabela 1 - Composição percentual das rações experimentais

\begin{tabular}{|c|c|c|c|c|c|}
\hline \multirow[b]{2}{*}{ Alimento $(\%)$} & \multicolumn{5}{|c|}{ Energia digestível (kcal/kg de ração) } \\
\hline & 2.700 & 2.950 & 3.200 & 3.450 & 3.700 \\
\hline Farelo de soja ${ }^{1}$ & 70,75 & 70,02 & 70,91 & 71,81 & 72,70 \\
\hline Milho $^{1}$ & 17,68 & 24,93 & 19,43 & 13,92 & 8,42 \\
\hline Óleo de soja ${ }^{1}$ & 0,00 & 0,61 & 5,21 & 9,80 & 14,39 \\
\hline abugo de milho & 7,11 & 0,00 & 0,00 & 0,00 & 0,00 \\
\hline osfato bicálcico & 1,84 & 1,77 & 1,81 & 1,85 & 1,90 \\
\hline alcáreo calcítico & 1,12 & 1,16 & 1,13 & 1,11 & 1,08 \\
\hline Suplemento min.+vit. ${ }^{2}$ & 1,00 & 1,00 & 1,00 & 1,00 & 1,00 \\
\hline Sal comum & 0,5 & 0,50 & 0,50 & 0,50 & 0,50 \\
\hline Antioxidante (BHT) & 0,01 & 0,01 & 0,01 & 0,01 & 0,01 \\
\hline \multicolumn{6}{|l|}{ Nutriente } \\
\hline álcio $(\%)$ & 1,0 & 1,0 & 1,00 & 1,00 & 1,00 \\
\hline osforo total $(\%)$ & 0,80 & 0,80 & 0,80 & 0,80 & 0,80 \\
\hline Cinzas $(\%)$ & 8,43 & 8,34 & 8,35 & 8,35 & 8,35 \\
\hline mido $(\%)$ & 20,56 & 24,99 & 21,68 & 18,37 & 15,06 \\
\hline ibra bruta $(\%)$ & 6,95 & 4,62 & 4,57 & 4,52 & 4,47 \\
\hline ordura total $(\%)$ & 1,62 & 2,44 & 6,81 & 11,18 & 15,55 \\
\hline $\begin{array}{l}\text { Energia digestível } \\
(\mathrm{kcal} / \mathrm{kg})\end{array}$ & 2.700 & 2.950 & 3.200 & 3.450 & 3.700 \\
\hline Proteína digestível (\%) & 31,12 & 31,33 & 31,31 & 31,30 & 31,28 \\
\hline Proteína bruta $(\%)$ & 35,00 & 35,00 & 35,00 & 35,00 & 35,00 \\
\hline \multicolumn{6}{|c|}{$\begin{array}{l}{ }^{1} \text { De acordo com os valores de digestibilidade descritos por Boscolo et al } \\
(2002) \text {. } \\
2 \text { Níveis de garantia por quilograma do produto (Rovimix peixes): vitamina } \mathrm{A}- \\
500.000 \mathrm{UI} \text {; vitamina D }-200.000 \mathrm{UI} \text {; vitamina } \mathrm{E}-5.000 \mathrm{mg} \text {; vitamina } \mathrm{K} 3- \\
1.000 \mathrm{mg} \text {; vitamina } \mathrm{B} 1-1.500 \mathrm{mg} \text {; vitamina } \mathrm{B} 2-1.500 \mathrm{mg} \text {; vitamina } \mathrm{B} 6 \\
1.500 \mathrm{mg} \text { - vitamina } \mathrm{B} 12-4.000 \mathrm{mg} \text {; ácido fólico }-500 \mathrm{mg} \text {; pantotenato de } \\
\text { cálcio }-4.000 \mathrm{mg} \text {; vitamina } \mathrm{C}-15.000 \mathrm{mg} \text {; biotina }-50 \mathrm{mg} \text {; inositol }-10.000 \\
\text { nicotinamida }-7.000 \mathrm{mg} \text {; colina }-40.000 \mathrm{mg} \text {; cobalto }-10 \mathrm{mg} \text {; cobre }-500 \mathrm{mg} \\
\text { ferro }-5.000 \mathrm{mg} \text {; iodo }-50 \mathrm{mg} \text {; manganês }-1500 \mathrm{mg} \text {; selênio }-10 \mathrm{mg} \text {; zinco - } \\
5.000 \mathrm{mg} \text {. }\end{array}$} \\
\hline
\end{tabular}


Os animais foram alimentados diariamente, duas vezes ao dia (Siddiqui et al., 1998; El-Sayed et al., 2005), às $10 \mathrm{he}$ às $16 \mathrm{~h}$, com taxa diária de arraçoamento de $1 \%$ da biomassa (Bhujel, 2000). A taxa de arraçoamento foi corrigida a cada 17 dias a partir de biometrias.

Durante o período de condicionamento, machos e fêmeas foram mantidos isolados, em descanso reprodutivo, por um período de 12 dias (Tacon et al., 1996). Após este período os machos foram transferidos para os hapas das fêmeas para o acasalamento, que teve duração de cinco dias (MacIntosh \& Little, 1995).

Ao término do acasalamento, foram coletados os ovos fertilizados de todas as fêmeas, individualmente, conforme metodologia descrita por MacIntosh \& Little (1995). Durante esse procedimento, foram mensurados o peso e o comprimento dos peixes de ambos os sexos, por meio de balança digital e ictiômetro de precisão $(0,01 \mathrm{~g} \mathrm{e} 0,1 \mathrm{~cm}$, respectivamente). Em seguida, os reprodutores foram novamente separados em seus respectivos hapas para novo descanso reprodutivo. Esse procedimento foi repetido por 80 dias, a fim de condicionar os animais ao procedimento de colheita de ovos.

Diariamente, pela manhã, foi mensurada a amplitude térmica, por meio de um termômetro de mercúrio, de máxima e mínima, com precisão de $\pm 1^{\circ} \mathrm{C}$. Quinzenalmente, foram mensurados nos tanques onde estavam os hapas, em horários pré-determinados, os teores de oxigênio dissolvido da água (oxímetro digital Hanna F-HI 9147), às 6 h, e o pH da água (pHmetro digital Hanna F-HI 8424), às 6 h e às 16 h.

Após o período de condicionamento, de 80 dias, foi realizada novamente a colheita dos ovos para avaliação do percentual de fêmeas desovantes (fêmeas que apresentavam ovos na cavidade oral), do peso médio das fêmeas desovantes, do número total de ovos por fêmea desovante, do número de ovos por grama de fêmea desovante, do número de ovos por grama de fêmeas acasaladas (total de fêmeas no hapa durante o acasalamento, composto por fêmeas desovantes e outras que não apresentavam ovos na cavidade oral), do peso médio e do diâmetro médio dos ovos. Para isso, no momento da colheita, além da mensuração do peso e do comprimento padrão corporal e do volume total de ovos liberados, foram colhidas amostras $(2 \mathrm{~mL})$ dos ovos de cada fêmea desovante, que foram fixados em solução de formalina 4\% (adaptado de El-Sayed et al., 2003; El-Sayed et al., 2005). Em seguida, os ovos fixados foram pesados determinando-se os diâmetros menor, maior e médio em balança analítica $(0,0001 \mathrm{~g})$ e microscópio estereoscópio dotado de ocular micrométrica, a partir de amostras de 100 e 20 ovos fixados, respectivamente (adaptado de Lavens et al., 1999; Ballestrazzi et al., 2003).
Os ovos coletados foram submetidos a incubação artificial, segundo MacIntosh \& Little (1995), em incubadoras confeccionadas em PVC, com fundo cego e redondo, com volume útil de 3,5 L. Os ovos de cada unidade experimental foram incubados, separadamente, em uma única incubadora.

Utilizou-se um sistema de recirculação, com volume total de $3,5 \mathrm{~m}^{3}$ e troca de $30 \%$ do volume total da água do sistema por dia. A temperatura da água do sistema de incubação foi aquecida por meio de resistência elétrica acoplada a um termostato de precisão $\pm 1^{\circ} \mathrm{C}$, de modo a manter a temperatura da água entre 25 e $27^{\circ} \mathrm{C}$. Aproximadamente dois dias após o início da incubação, quando ocorreu a eclosão dos ovos, foram retiradas amostras de 20 larvas de cada incubadora para mensuração do peso úmido médio dos animais no momento da eclosão (adaptado de El-Sayed et al., 2003).

Após a eclosão dos ovos, foram utilizadas 500 larvas com 3 dias de idade para avaliar os efeitos das rações fornecidas aos reprodutores sobre o tempo de sobrevivência das proles ao jejum. As proles foram distribuídas em 20 aquários de $25 \mathrm{~L}$, cada um com 25 larvas. Para isso, foi considerado o tempo necessário para a mortalidade de $100 \%$ dos animais nos aquários (adaptado de Lavens et al., 1999). Três dias após a eclosão, quando os animais iniciaram o processo de natação superficial (MacIntosh \& Little, 1995), foi mensurada a taxa de sobrevivência à incubação, pela contagem do número total de larvas vivas em cada unidade experimental.

Os reprodutores foram novamente submetidos ao processo de descanso reprodutivo descrito anteriormente. Depois do período de descanso, todas as fêmeas foram sedadas em solução contendo óleo de cravo (Taylors \& Roberts, 1999), em concentração de $63 \mathrm{mg} / \mathrm{L}$ por três minutos (adaptado de Bard et al., 2004), para mensuração individual do peso e comprimento padrão.

Em seguida, as fêmeas foram submetidas à eutanásia por meio de choque térmico a aproximadamente $1^{\circ} \mathrm{C}$, pela imersão em água contendo gelo (adaptado de Bombardelli \& Hayashi, 2005a; Bombardelli \& Hayashi, 2005b), para dissecação e mensuração individual dos pesos do fígado, das gônadas e das vísceras.

A partir desses dados, foram avaliados os parâmetros zootécnicos de peso médio final, comprimento padrão médio final, ganho de peso médio, conversão alimentar aparente, índice hepatossomático, índice gonadossomático (Vazzoler, 1996) e índice viscerossomático.

Dos animais dissecados, foram separados aleatoriamente dois fígados de fêmeas de cada unidade experimental para avaliação histológica e determinação do percentual de 
deposição lipídica, totalizando oito fígados analisados por tratamento. Esses órgãos foram coletados e fixados em solução de Bouin aquoso durante 8 horas e posteriormente transferidos para solução de álcool a 70\%. Para o processamento, o material foi desidratado pela passagem em séries crescentes de álcool, diafanizados em xilol e incluídos em parafina para obtenção de cortes semisseriados transversais, com $5 \mu \mathrm{m}$ de espessura.

De cada fígado foram confeccionadas quatro lâminas, cada uma contendo cinco cortes histológicos, organizados de modo que, na sequência, o primeiro corte foi utilizado para coloração com hematoxilina-eosina e o corte seguinte com ácido periódico de Schiff (P.A.S.) (Figura 1), o que garantiu a confecção de duas lâminas para cada método de coloração por animal. Destas lâminas, foram utilizados para as análises morfométricas cinco cortes histológicos de cada coloração por animal, totalizando 40 campos microscópicos corados em H.E. analisados por tratamento e outros 40 campos corados em P.A.S.

O percentual de deposição lipídica foi estimado em análise morfométrica, tomando-se como medida padrão a área total do campo microscópico $\left(32.690,43 \mu \mathrm{m}^{2}\right)$ (Figura 2, A1) subtraída da área ocupada pela veia centrolobular (Figura 2 A2), sinusoides, núcleos e nucléolos (L1)
(Figura 2, B1 e B2). Definindo-se esta área, em seguida foi determinada a área marcada por glicogênio (L2) (Figura 2, $\mathrm{C} 1$ e C2). A diferença entre as áreas L1 e L2 indicou a área ocupada por lipídios.

A análise morfométrica foi realizada por meio de microscópio óptico Zeiss, em objetiva de 40X e as 400 imagens, obtidas e analisadas pelo pacote de análise de imagens Image Pro-Plus $4.5^{\circledR}$.

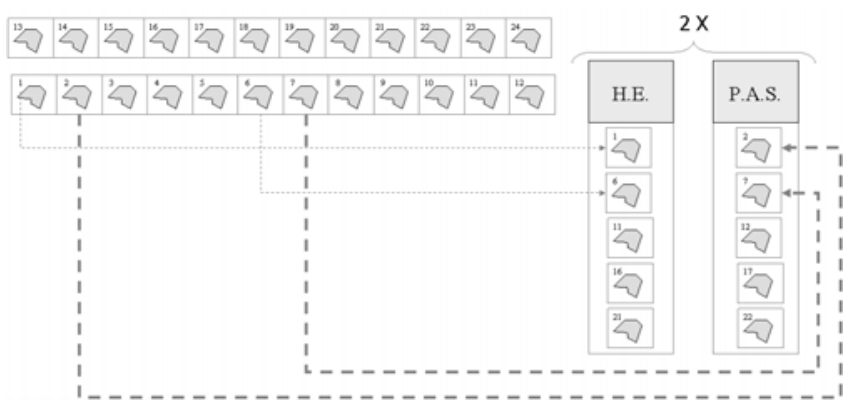

Figura 1 - Representação esquemática da sequência dos cortes histológicos do tecido hepático, corados em hematoxilina-eosina (HE) e ácido periódico de Schiff (P.A.S.) para realização das análises morfométricas.

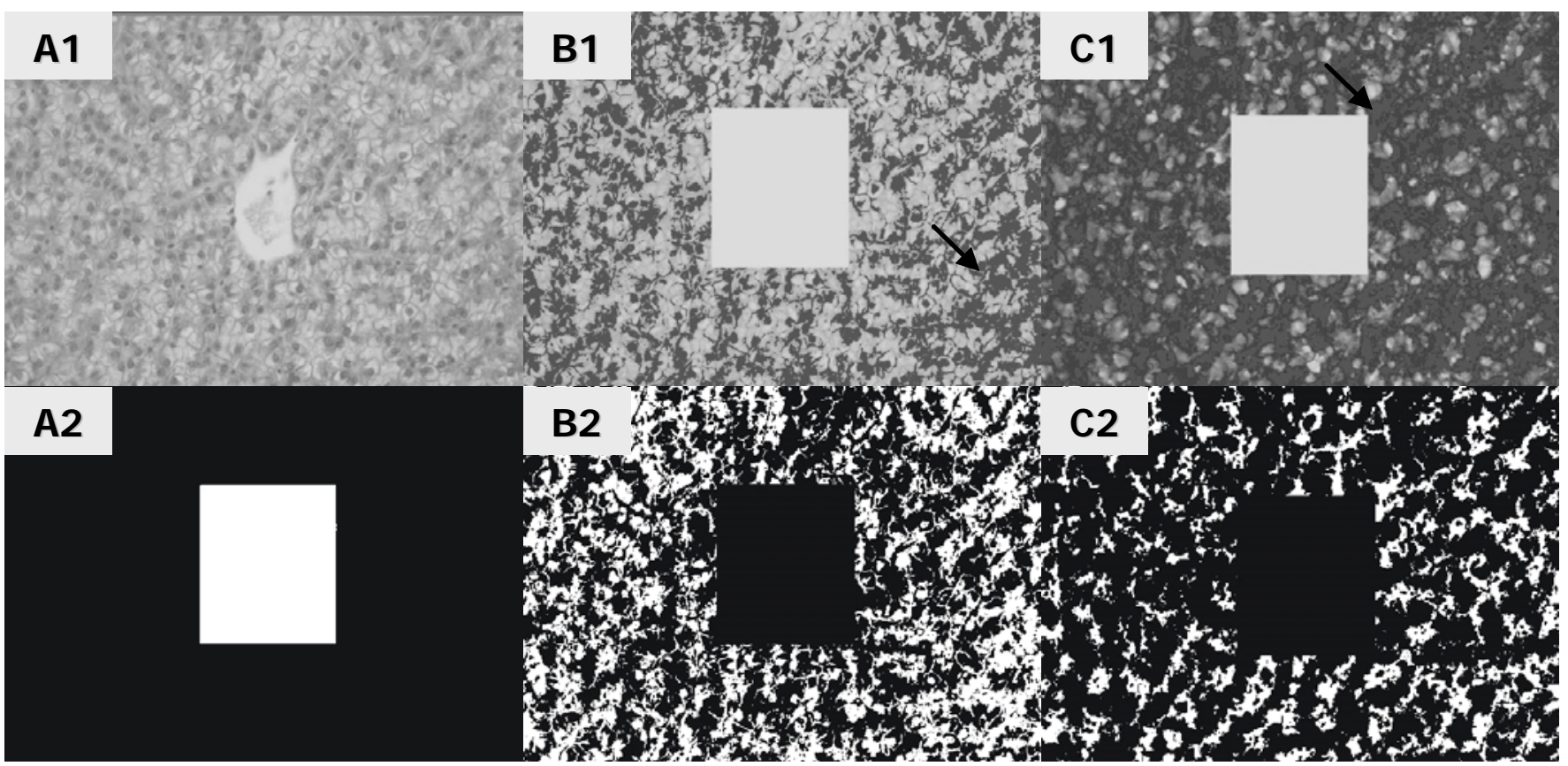

Figura 2 - Método de análise de imagem (morfometria) do fígado de peixes por meio do software Image Pró-Plus $4.5^{\circledR}$. A1 = imagem do campo microscópico corado em HE; A2 = negativo de imagem A1 marcando a área da veia centro-lobular; B1 = campo microscópico corado em HE marcando a área ocupada por sinusoídes; núcleos e nucléolos; B2= negativo da imagem $\mathrm{B} 1 ; \mathrm{C} 1$ = imagem do campo microscópico corado em P.A.S., marcando a área ocupada por glicogênio; $\mathrm{C} 2=$ negativo da imagem $\mathrm{C} 1$. As setas indicam a área marcada pelo software. 
Os dados obtidos foram inicialmente submetidos à análise de variância multivariada (MANOVA) a 5\% de significância e, quando evidenciado efeito significativo, foi aplicada a análise de variância (ANOVA), individualmente, para cada variável-resposta a 5\% de significância. As variáveis que sofreram efeito dos tratamentos foram submetidas ao protocolo de regressão linear múltipla utilizando-se o software Statistica $7.0^{\circledR}$.

\section{Resultados e Discussão}

Os valores mínimo e máximo da temperatura da água nos tanques de reprodutores foram de $26,7 \pm 1,0$ e $30,2 \pm 1,2^{\circ} \mathrm{C}$, respectivamente, e concentração média de oxigênio dissolvido, de $6,11 \pm 1,05 \mathrm{mg} / \mathrm{L}$. Esses parâmetros são adequados para a reprodução (Bhujel, 2000) e o desenvolvimento embrionário inicial de tilápias (Rana, 1988; Rana, 1990), quando os ovos são incubados naturalmente no boca das fêmeas, ainda nos tanques de acasalamento.

Os valores médios de $\mathrm{pH}$ da água foram 7,50 $\pm 0,09$ pela manhã e 9,33 $\pm 0,06$ pela tarde. Apesar de esses valores serem adequados para o crescimento da espécie (Little \& Hulata, 2000; Ross, 2000), não existem informações sobre os efeitos destes parâmetros na reprodução de tilápias (Bhujel, 2000).

O percentual de fêmeas desovantes verificados neste experimento (Tabela 2) variou de 44,05 a $68,33 \%$ e pode ser considerado satisfatório. Bhujel (2000), em revisão, relatou percentuais de fêmeas desovantes de 29,39 e $42 \%$ quando estocadas em densidade de 10,5 e 2,5 fêmeas $/ \mathrm{m}^{2}$, respectivamente. Siddiqui et al. (1998) alimentaram reprodutores de tilápia-do-nilo com rações contendo aproximadamente $3.100 \mathrm{kcal}$ de energia digestível/kg e diferentes níveis de proteína bruta por um período de 196 dias e não verificaram efeito dos níveis de energia digestível sobre o intervalo de desovas. Contudo, segundo os autores, em torno de $60 \%$ das fêmeas desovaram a cada duas semanas.

El-Sayed et al. (2005) estudaram os efeitos de diversas fontes de óleo na nutrição de reprodutores de tilápia-donilo (Oreochromis niloticus) mantidos em diferentes salinidades. No experimento, esses autores alimentaram os peixes com rações isoproteicas $(40 \% \mathrm{~PB})$ e isocalóricas $(18,6 \mathrm{MJ}$ ou $4.445,40 \mathrm{kcal} / \mathrm{kg})$ por 165 dias e também não verificaram efeito das fontes de óleo de soja, do óleo de peixe e da mistura de ambos sobre o intervalo entre as desovas e a fecundidade nos animais criados em água doce. O mesmo foi verificado por El-Sayed et al. (2003), em estudo sobre os efeitos de diversos níveis de proteína dietética para reprodutores desta espécie em diferentes salinidades.

Apesar de a fecundidade não ter sido influenciada $(\mathrm{P}>0,05)$ pelos níveis de energia digestível, em valores absolutos, a ração contendo $3.200 \mathrm{kcal}$ de energia digestível/kg resultou em produção média de 5,47 ovos $/ \mathrm{g}$ de fêmea acasalada (Tabela 2), equivalente a 321,76 ovos $/ \mathrm{kg}$ de fêmea acasalada por dia. Esses resultados são próximos aos sugeridos como adequados, de 350 ovos $/ \mathrm{kg}$ de fêmea acasalada por dia (MacIntosh \& Little, 1995) quando os reprodutores de tilápia-do-nilo (Oreochromis niloticus) tem dez dias de descanso e cinco de acasalamento. A variação na produção de ovos entre os trabalhos pode estar relacionada ao grupo de reprodutores utilizado, haja vista as variações intraespecíficas existentes (Coward et al., 2002).

O tamanho individual das fêmeas ao término do período experimental pode ter influenciado os resultados de fecundidade, uma vez que, apesar de as fêmeas apresentarem peso médio semelhante $(\mathrm{P}>0,05)$ entre os níveis de energia digestível testados (Tabela 2), a variação individual de tamanho, considerando as taxas reprodutivas diferenciadas e inconstantes ao longo do experimento, promoveu resultados de fecundidade absoluta e relativa diferenciados,

Tabela 2 - Desempenho reprodutivo de fêmeas de tilápia-do-nilo (Oreochromis niloticus L.) alimentadas com rações contendo diversos níveis de energia digestível

\begin{tabular}{|c|c|c|c|c|c|c|}
\hline \multirow[t]{2}{*}{ Item } & \multicolumn{5}{|c|}{ Energia digestível (kcal/kg de ração) } & \multirow[b]{2}{*}{$\mathrm{P}^{*}$} \\
\hline & 2.700 & 2.950 & 3.200 & 3.450 & 3.700 & \\
\hline Peso de fêmeas desovantes (g) & 152,20 & 154,45 & 156,65 & 158,02 & 152,89 & 0,93 \\
\hline Percentual de fêmeas desovantes (\%) & 52,86 & 56,67 & 68,33 & 44,05 & 46,67 & 0,11 \\
\hline Fecundidade absoluta (x10 ovos/fêmea) & 126,46 & 124,08 & 126,80 & 146,32 & 117,12 & 0,31 \\
\hline Fecundidade relativa (ovos/g fêmea) & 8,27 & 8,31 & 8,10 & 9,27 & 7,75 & 0,24 \\
\hline Fecundidade relativa (ovos/g de fêmea acasalada) & 4,17 & 4,50 & 5,47 & 3,92 & 3,49 & 0,21 \\
\hline Peso dos ovos (mg) & 4,78 & 4,69 & 4,66 & 4,86 & 4,49 & 0,32 \\
\hline Diâmetro médio dos ovos (mm) & 2,24 & 2,22 & 2,25 & 2,30 & 2,25 & 0,14 \\
\hline Peso das larvas no momento da eclosão (mg) & 5,13 & 5,11 & 5,08 & 5,13 & 5,02 & 0,88 \\
\hline Taxa de sobrevivência durante o período de incubação (\%) & 69,88 & 74,65 & 74,49 & 71,48 & 71,57 & 0,07 \\
\hline Tempo de sobrevivência ao jejum $(\text { dias })^{1}$ & 16,00 & 18,85 & 15,75 & 20,75 & 21 & 0,02 \\
\hline
\end{tabular}

${ }^{*} \mathrm{P}=\mathrm{P}$-valor; ${ }^{1} \mathrm{y}=2,454+0,005 \mathrm{X} ; \mathrm{R}^{2}=0,355$. 
o que levou a maior dispersão dos dados, que variaram em média de 1.171,20 a 1.463,20 ovos/fêmeas desovante, de 7,75 a 9,27 ovos/g de fêmea desovante e de 3,49 a 5,47 ovos/g de fêmea acasalada (Tabela 2).

Os pesos e diâmetros médios dos ovos, a taxa de sobrevivência durante o período de incubação e o peso médio das larvas no momento da eclosão também não foram influenciados $(\mathrm{P}>0,05)$ pelos níveis de energia digetível (Tabela 2).

El-Sayed et al. (2005) também verificaram ausência de efeito das fontes de óleo para reprodutores de tilápiado-nilo sobre o diâmetro médio dos ovos e a taxa de sobrevivência durante o período de incubação. Resultados semelhantes aos deste estudo foram verificados por El-Sayed et al. (2005), de 2,27 a 2,34 mm e 49,71 a 61,43\%, respectivamente. Coward \& Bromage (2000) sugeriram que as médias do menor e do maior diâmetro dos ovos de tilápias-do-nilo são de 2,25 e 2,95 mm, respectivamente.

Os resultados obtidos nesta pesquisa indicam que o aumento energético das rações amplia o tempo necessário para ocorrer $100 \%$ de mortalidade de larvas em jejum (Tabela 2). Essa melhora na qualidade larval pode estar relacionada ao vigor das proles e, possivelmente, ocorreu em razão da maior deposição de nutrientes da dieta das fêmeas para os ovócitos durante a vitelogênese. Em reprodutores de truta arco-íris (Oncorhynchus mikiss), a substituição do óleo de peixe pelo de amendoim promoveu maior deposição de ácidos graxos saturados nos ovos (Ballestrazzi et al., 2003), confirmando a importância da alimentação durante a vitelogênese. Ao contrário, dietas com diversos níveis de ácidos graxos n-3 e suplementação com vitaminas C e E para reprodutores de "turbot" (Scopththalmus maximus) não influenciaram a taxa de sobrevivência das larvas ao jejum.

Os resultados de peso médio das fêmeas desovantes (Tabela 2), peso e comprimento padrão final médios, ganho de peso médio e conversão alimentar aparente (Tabela 3 ) não variaram $(\mathrm{P}>0,05)$ entre as dietas. Esses resultados eram esperados, uma vez que a taxa de arraçoamento e a frequência de alimentação empregada foram adequadas para o bom desempenho reprodutivo da espécie (Bhujel, 2000), e não para o máximo desempenho em ganho de peso e crescimento. Isso pode ser observado, especialmente, em relação à conversão alimentar aparente (Tabela 3 ), cujos valores foram elevados $(2,11$ a 3,36$)$, basicamente porque as fêmeas em atividade reprodutiva destinam grande parte de suas reservas energéticas para a reprodução, e não para o crescimento.

Os índices hepatossomático, gonadossomático e viscerossomático verificados neste experimento não foram influenciados $(\mathrm{P}>0,05)$ pelos níveis de energia digestível das rações (Tabela 3 ).

O período ( 80 dias) no qual os peixes foram alimentados com as rações experimentais pode estar relacionado à ausência de efeito sobre os parâmetros reprodutivos, zootécnicos, larvais e ainda os índices hepatossomático, gonadossomático e viscerossomático, especialmente por ter sido curto, uma vez que o tempo de alimentação é de grande importância para garantir a influência das dietas sobre a reprodução. Ao contrário, Siddiqui et al. (1998) observaram efeito dos níveis de energia digestível sobre a fecundidade de tilápias-do-nilo alimentadas por 196 dias com rações com diversos níveis de proteína. Em jundiácinza (Rhamdia quelen) alimentado por somente 70 dias antes do período reprodutivo com rações contendo diferentes fontes lipídicas, Parra (2007) registrou alteração na morfometria dos ovos e sobrevivência larval, em decorrência das dietas. Os resultados comprovam a importância do tempo de alimentação dos reprodutores e a influência das espécies nos resultados.

Para garantir respostas efetivas sobre o desempenho reprodutivo, a alimentação dos reprodutores deve abranger,

Tabela 3 - Desempenho zootécnico de fêmeas de tilápia-do-nilo (Oreochromis niloticus L.) alimentadas com rações contendo diversos níveis de energia digestível

\begin{tabular}{|c|c|c|c|c|c|c|}
\hline \multirow[t]{2}{*}{ Variável } & \multicolumn{5}{|c|}{ Energia digestível (kcal/kg de ração) } & \multirow[b]{2}{*}{$\mathrm{P}^{*}$} \\
\hline & 2.700 & 2.950 & 3.200 & 3.450 & 3.700 & \\
\hline Peso inicial (g) & 114,43 & 109,97 & 111,33 & 115,00 & 113,37 & 0,08 \\
\hline Comprimento padrão inicial $(\mathrm{cm})$ & 15,00 & 14,88 & 14,99 & 15,13 & 15,15 & 0,09 \\
\hline Peso final médio $(\mathrm{g})$ & 154,53 & 156,10 & 159,20 & 161,81 & 161,42 & 0,48 \\
\hline Comprimento padrão final $(\mathrm{cm})$ & 16,85 & 16,88 & 17,16 & 17,30 & 17,16 & 0,24 \\
\hline Ganho de peso médio $(\mathrm{g})$ & 8,27 & 13,83 & 8,47 & 10,05 & 9,82 & 0,21 \\
\hline Conversão alimentar aparente (g/g) & 3,22 & 2,11 & 3,36 & 2,60 & 2,91 & 0,33 \\
\hline Índice hepatossomático (\%) & 1,80 & 1,88 & 1,93 & 1,85 & 1,97 & 0,38 \\
\hline Índice gonadossomático (\%) & 4,01 & 3,90 & 3,77 & 3,63 & 3,94 & 0,92 \\
\hline Índice viscerossomático (\%) & 5,77 & 5,96 & 6,16 & 6,06 & 6,06 & 0,99 \\
\hline
\end{tabular}

${ }^{*} \mathrm{P}=\mathrm{P}$-valor 
no mínino, o período vitelogênico (Navas et al., 1997), que influencia especialmente a incorporação dos lipídios nos ovócitos (Wiegand, 1996; Izquierdo et al., 2001) por meio do precursor hepático, a vitelogenina (Tyler \& Sumpter, 1996; Coward et al., 2002; Kim \& Takemura, 2002).

$\mathrm{O}$ fato de o emprego da fonte de proteína das rações experimentais ter sido unicamente de origem vegetal provavelmente não teve influência negativa. Estudos prévios têm comprovado que os níveis plasmáticos de esteróides sexuais (17 $\beta$-estradiol), os índices epatossomático e gonadossomático e a presença de ovócitos maduros são afetados pela substituição total de farinha de peixe por farelo de soja em rações para fêmeas de tilápia-do-nilo somente a partir da $20^{-}$semana de criação (FontaínhasFernandes et al., 2000).

As análises histológicas do tecido hepático submetido à coloração em hematoxilina-eosina não evidenciaram alterações das estruturas morfológicas, tampouco a presença de infiltrados inflamatórios. Isso sugere preservação dessas estruturas, independentemente dos tratamentos, contudo, foi evidenciada relação diretamente proporcional $(\mathrm{P}<0,05)$ entre os níveis de energia digestível das rações e o percentual de deposição lipídica nos hepatócitos (Figura 3).

Alterações do tecido hepático semelhantes às verificadas neste experimento foram constatadas por Caballero et al. (2004) ao estudarem os efeitos da substituição do óleo de peixe pelo óleo de soja em rações para "sea bream" (Sparus aurata L.). Esses autores verificaram que o uso de elevados níveis de óleo de soja nas rações causou alterações histológicas do tecido hepático, especialmente quanto ao aumento do volume de lipídios e à ocorrência de quadros

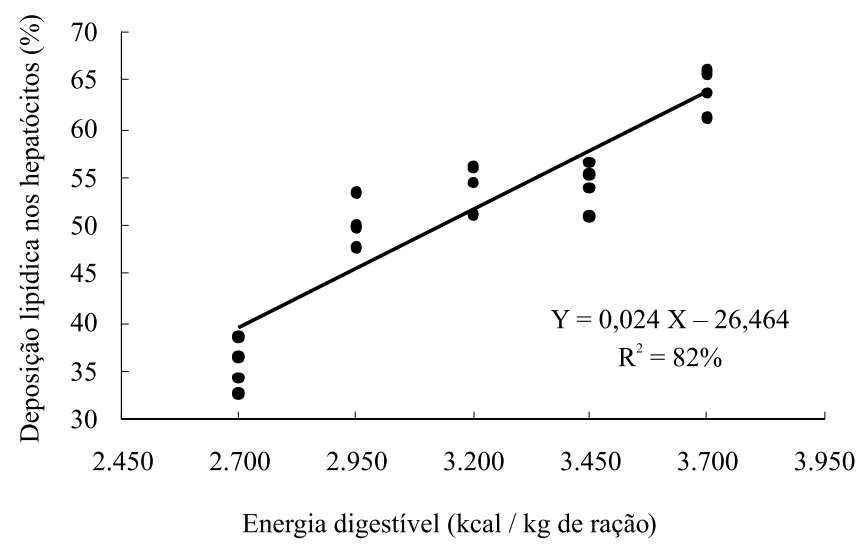

Figura 3 - Área percentual de deposição de lipídios em hepatócitos de fêmeas de tilápia-do-nilo (Oreochromis niloticus L.) alimentadas com rações contendo diferentes níveis de energia digestível. $\mathrm{P}=0,02$. clínicos de esteatose nos hepatócitos. Ruyter et al. (2006) verificaram efeitos semelhantes no salmão-do-atlântico (Salmo salar). Caballero et al. (2004), tomando como base estudos com ratos, discutiram a possibilidade de esse acúmulo de lipídios nos hepatócitos estar relacionado ao aumento da atividade lipogênica promovida pelo ácido graxo linoleico, proveniente do óleo de soja. Além disso, dietas ricas neste ácido graxo induzem ao aumento de triacilgliceróis no soro e no fígado, por reduzirem a capacidade de sua oxidação. Dessa forma, animais em situações similares podem apresentar perda ou redução da disponibilidade de energia metabólica.

Por outro lado, a substituição de até $50 \%$ do óleo de peixe por óleo de soja em rações para juvenis de "sea bass" (Dicentrarchus labrax) e truta arco-íris (Oncorhynchus mikiss) não promove alterações histológicas do fígado (Figueiredo-Silva et al., 2005).

Os resultados histológicos obtidos com os níveis energéticos impostos neste trabalho eram esperados e poderiam ser mais pronunciados em períodos experimentais mais longos.

\section{Conclusões}

Os níveis de energia digestível utilizados nas rações, obtidos com a inclusão do óleo de soja, não influenciam os parâmetros reprodutivos e zootécnicos de fêmeas de tilápiado-nilo alimentadas por 80 dias, contudo, aumentam a resistência das larvas quando expostas a jejum e melhoram a deposição lipídica nos hepatócitos.

\section{Literatura Citada}

ALCESTE, C.; JORRY, D.E. Análisis de las tendencias actuales en la comercialización de tilapia en los Estados Unidos de Norteamérica y la Unión Europea. In: AQUICULTURA BRASIL, 10., 1998, Recife. Anais... Recife: Associação Brasileira de Aquicultura, 1998. p.349-364.

AL-HAFEDH, Y.S.; SIDDIQUI, A.Q.; AL-SAIADY, M.Y. Effects of dietary protein levels on gonad maturation, size and age at first maturity, fecundity and growth of Nile tilapia. Aquaculture International, v.7, p.319-332, 1999.

ALMANSA, E.; PÉRZ, M.J.; CEJAS, J.R. et al. Influence of broodstock gilthead seabream (Sparus aurata L.) dietary fatty acids on egg quality and egg fatty acid composition throughou the spawning season. Aquaculture, v.170, p.323-336, 1999.

ASTURIANO, J.F.; SORBERA, L.A.; CARRILO, M. et al. Reproductive performance in male European sea bass (Dicentrarchus labrax, L.) fed two PUFA - enriched experimental diets: a comparison with males fed a wet diet. Aquaculture, v.194, p.173-190, 2001.

BALLESTRAZZI, R.; RAINIS, S.; TULLI, F. et al. The effect of dietary coconut oil on reproductive traits and egg fatty acid composition in rainbow trout (Oncorhynchus mykiss). Aquaculture International, v.11, p.289-299, 2003. 
BARD, J.; ASSUMPÇÃO, L.; SCHAEFFER, L. et al. Emprego de óleo de cravo na indução à anestesia de juvenis de tilápia-doNilo (Oreochromis niloticus). In: SIMPÓSIO PARANAENSE DE ENGEnharia DE PESCA, 2., 2004, Toledo. Anais... Toledo: Simpósio Paranaense de Engenharia de Pesca/Gmosis, [2004]. (CD-ROM).

BELL, J.G.; FARNDALE, B.M.; BRUCE, M.P. et al. Effects of broodstock dietary lipid on fatty acid composition of eggs from sea bass (Dicentrarchus labrax). Aquaculture, v.149, p.107-119, 1997.

BHUJEL, R.C. A review of strategies for the management of Nile tilapia (Oreochromis niloticus) broodfish in seed production systems, especially hapa-based systems. Aquaculture, v.181, p. 37-59, 2000 .

BHUJEL, R.C.; YAKUPITIYAGE, A.; TURNER, W.A. et al. Selection of a commercial feed for Nile tilapia (Oreochromis niloticus) broodfish breeding in a hapa - in - pond system. Aquaculture, v.194, p.303-314, 2001.

BOMBARDELLI, R.A.; HAYASHI, C. Feminilização de larvas de tilápia-do-Nilo (Oreochromis niloticus L.) a partir de banhos de imersão com valerato-de-estradiol. Revista Brasileira de Zootecnia, v.34, n.2, p.357-364, 2005a.

BOMBARDELLI, R.A.; HAYASHI, C. Masculinização de larvas de tilápia-do-Nilo (Oreochromis niloticus L.) a partir de banhos de imersão com $17 \alpha$-metiltestosterona. Revista Brasileira de Zootecnia, v.34, n.2, p.365-372, 2005b.

BORGHETTI, N.R.B.; OSTRENSKY, A.; BORGHETTI, J.R. Aquicultura - Uma visão geral sobre a produção de organismos aquáticos no Brasil e no mundo. Curitiba: Grupo Integrado de Aqüicultura e Estudos Ambientais, 2003. 128p.

BOSCOLO, W.R.; HAYASHI, C.; MEURER, F. Digestibilidade aparente da energia e nutrientes de alimentos convencionais e alternativos para o tilápia-do-Nilo (Oreochromis niloticus). Revista Brasileira de Zootecnia, v.31, n.2, p.539-545, 2002.

BROMAGE, N. Broodstcok management and seed quality - general considerations. In: BROMAGE, N.R.; ROBERTS, R.J. (Eds.) Broodstock management and egg and larval quality. London: Blackwell Science Ltda., 1995. p.1-25.

BROOKS, S.; TYLER, C.R.; SUMPTER, J.P. Egg quality in fish: what makes a good egg? Reviews in Fish Biology and Fisheries, v.7, p.287-416, 1997

CABALlERO, M.J.; IZQUIERDO, M.S.; KJORSVIK, E. et al. Histological alterations in the liver of sea bream, Sparus auratus L., caused by short- or long - term feeding with vegetable oils as the sole lipid source. Journal of Fish Disease, v.27, p.531541,2004

COWARD, K.; BROMAGE, N.R. Reproductive physiology of female tilapia broodstock. Reviews in Fish Biology and Fisheries, v. 10, p.1-25, 2000.

COWARD, K.; BROMAGE, N.R.; HIBBITT, O. et al. Gamete physiology, fertilization and egg activation in teleost fish. Reviews in Fish Biology and Fisheries, v.12, p.33-58, 2002.

CRESCÊNCIO, R. Ictiofauna brasileira e seu potencial para criação. In: BALDISSEROTTO, B.; GOMES, L.C. (Eds.). Espécies nativas para piscicultura no Brasil. Santa Maria: Editora UFSM, 2005. p.23-36.

EL-SAYED, A.M.; MANSOUR, C.R.; EZZAT, A.A. Effects of dietary protein level on spawning performance of Nile tilapia (Oreochromis niloticus) broodstock reared at different water salinities. Aquaculture, v.220, p.619-632, 2003.

EL-SAYED, A.M.; MANSOUR, C.R.; EZZAT, A.A. Effects of dietary lipid source on spawning performance of Nile tilapia (Oreochromis niloticus) broodstock reared at different water salinities. Aquaculture, v.248, p.187-196, 2005.

FIGUEIREDO-SILVA, A.; ROCHA, E.; DIAS, J. et al. Partial replacement of fish oil by soybean oil on lipid distribution and liver histology in European sea bass (Dicentrarchus labrax) and rainbow trout (Oncorhynchus mikiss) juveniles. Aquaculture Nutrition, v.11, p.147-155, 2005.
FONTAINHAS-FERNANDES, A.; MONTEIRO, M.; FIGUEIREDO, A. et al. Partial or total replacement of fish meal by plant protein affects gonadal development and plasma $17 \beta$-estradiol levels in female Nile tilapia. Aquaculture International, v.8, p.299-313, 2000.

GUNASEKERA, R.M.; LAM, T.J. Influence of dietary protein level on ovarian recrudescence in Nile tilapia, Oreochromis niloticus (L.). Aquaculture, v.149, p.57-69, 1997.

GUNASEKERA, R.M.; SHIM, K.F.; LAM, T.J. Effects of dietary protein level on puberty, oocyte growth and egg chemical composition in the tilapia, Oreochromis niloticus (L.). Aquaculture, v.134, p.169-183, 1995.

GUNASEKERA, R.M.; SHIM, K.F.; LAM, T.J. Influence of protein content of broodstock diets on larval quality and performance in Nile tilapia, Oreochromis niloticus (L.). Aquaculture, v.146, p.245-259, 1996.

GUNASEKERA, R.M.; SHIM, K.F.; LAM, T.J. Influence of dietary protein content on the distribution of amino acids in oocytes, serum and muscle of Nile tilapia, Oreochromis niloticus (L.). Aquaculture, v.152, p.205-221, 1997.

HARDY, R.W. Collaborative opportunities between fish nutrition and other disciplines in aquaculture: an overview. Aquaculture, v.177, p.217-230, 1999.

HAYASHI, C.; BOSCOLO, W.R.; SOARES, C.M. et al. Uso de diferentes graus de moagem dos ingredientes em dietas para tilápia-do-Nilo (Oreochromis niloticus L.) na fase de crescimento. Acta Scientiarum, v.21, n.3, p.733-737, 1999.

INSTITUTO BRASILEIRO DO MEIO AMBIENTE E DOS RECURSOS NATURAIS RENOVÁVEIS - IBAMA. Estatística da Pesca 2005 Brasil - Grandes Regiões e Unidades da Federação. Brasília: IBAMA, 2007. 108p.

IZQUIERDO, M.S.; FERNANDEZ-PALACIOS, H.; TACON, A.G.J. Effect of broodstock nutrition on reproductive performance of fish. Aquaculture, v.197, p.25-42, 2001.

KIM, B.; TAKEMURA, A. In vitro vitellogenin synthesis in primary cultures of tilapia hepatocytes. Fisheries Science, v. 68 , p.123-131, 2002.

LAVENS, P.; LEBEGUE, E.; JAUNET, H. et al. Effects of dietary essencial fatty acids and vitamins on egg quality in turbot broodstocks. Aquaculture International, v.7, p.225-240, 1999.

LITTLE, D.C.; HULATA, G. Strategies for tilapia seed production. In: BEVERIDGE, M.C.M.; MCANDREW, B.J. (Eds.). Tilapia: biology and exploitation. Dordrecht: Kluwer Academic Publisher, 2000. p.226-326.

LITTLE, D.C.; TURNER, W.A.; BHUJEL, R.C. Commercialization of a hatchery process to produce MT-treated Nile tilapia in Thailand. In: SIMPÓSIO CENTROAMERICANO DE ACUACUltura, 4., 1997, Honduras. Anais... Honduras: Sociedade Centro Americana de Acuacultura, 1997. p.108-118

MACINTOSCH, D.J.; LITTLE, D.C. Nile tilapia (Oreochromis niloticus). In: BROMAGE, N.R.; ROBERTS, R.J. (Eds.). Broodstock management and egg and larval quality. London: Blackwell Science Ltda., 1995. p.277-320.

MAZORRA, C.; BRUCE, M.; BELL, J.G. et al. Dietary lipid enhancement of broodstock reproductive performance and egg and larval quality in Atlantic halibut (Hippoglossus hipoglossus). Aquaculture, v.227, p.21-33, 2003.

MEURER, F.; BOMBARDELLI, R.A.; HAYASHI, C. et al. Grau de moagem dos alimentos em rações para a tilápia-do-nilo (Oreochromis niloticus) durante o período de reversão sexual Acta Scientiarum, v.27, n.1, p.81-85, 2005.

NAVAS, J.M.; BRUCE, M.; THRUSH, M. et al. The impact of seasonal alteration in the lipid composition of broodstock diets on egg quality in the European sea bass. Journal of Fish Biology, v.51, p.760-773, 1997.

PARRA, J.E.G. Respostas reprodutivas de fêmeas de jundiá (Rhamdia quelen) alimentadas com diferentes fontes protéicas e lipídicas. 2007. 93f. Tese (Doutorado em Zootecnia) - Universidade Federal de Santa Maria, 2007. 
RANA, K. Reproductive biology and the hatchery rearing of tilapia eggs and fry. In: MUIR, J.F.; ROBERTS, R. (Eds.) Recents advances in aquaculture. New York: Timber Press, 1988. v.3, p.343-406.

RANA, K. Influence of incubation temperature on Oreochromis niloticus (L.) eggs and fry. I. Gross embryology, temperature tolerance and rates of embryonic development. Aquaculture, v.87, p.165-181, 1990.

ROSS, L.G. Environmental physiology and energetics. In: BEVERDGE, M.C.M.; MCANDREW, B.J. (Eds.) Tilapias: biology and exploitation. London: Kluwer Academic Publishers, 2000. p.89-128.

RUYTER, B.; MOYA-FALCÓN, C.; ROSEnLUnd, G. et al. Fat contend and morphology of liver and intestine of Atlantic salmon (Salmo salar): effects of temperature and dietary soybean oil. Aquaculture, v.252, p.441-452, 2006.

SANTIAGO, C.B.; LARON, M.A. Growth and fry production of Nile tilapia, Oreochromis niloticus (L.), on different feeding schedules. Aquaculture Research, v.33, p.129-136, 2002.

SARGENT, J.; MCEVOY, L.; ESTEVEZ, A. et al. Lipid nutrition of marine fish during early development: current status and future directions. Aquaculture, v.179, p.217-229, 1999.

SARGENT, J.R. Origins and functions of egg lipids: nutritional implications. In: BROMAGE, N.R.; ROBERTS, R.J. (Eds.) Broodstock management and egg and larval quality. London: Blackwell Science Ltda., 1995. p.353-372.

SIDDIQUI, A.Q.; AL-HAFEDH, Y.S.; ALI, S.A. Effect of dietary protein level on the reproductive performance of Nile tilapia, Oreochromis niloticus (L.). Aquaculture Research, v.29, p.349-358, 1998.

TACON, P.; NDIAYE, P.; CAUTY, C. et al. Relationships between the expression of maternal behavior and ovarian development in the mouthbrooding cichlid fish Oreochromis niloticus Aquaculture, v.146, p.261-275, 1996.

TAYLORS, P.W.; ROBERTS, S.D. Clove oil: an alternative anesthetic for aquaculture. North American Journal of Aquaculture, v.61, p.150-155, 1999.

TYLER, C.R.; SUMPTER, J.P. Oocyte growth and development in teleosts. Reviews in Fish Biology and Fisheries, v.6, p.287$318,1996$.

VASSALO-AGIUS, R.; WATANABE, T.; YOSHIZAKI, G. et al. Quality of eggs and spermatozoa of Rainbow trout fed an n-3essential fatty acid-deficient diet and its effects o the lipid and fatty acid components of eggs, semen and livers. Fisheries Science, v.67, p.818-827, 2001.

VAZZOLER, A.E.A.M. Biologia da reprodução de peixes teleósteos: teoria e prática. Maringá: EDUEM, 1996. 169p.

WATANABE, T. Importance of the study of broodstock nutrition for further development of aquaculture. In: COWEY, C.B.; MACKIE, A.M.; BELL, J.G. (Eds.) Nutrition and feeding in fish. London: Academic Press, 1985. p.395-414.

WATANABE, T.; VASSALO-AGIUS, R. Broodstock nutrition research on marine finfish in japan. Aquaculture, v.227, p.35-61, 2003.

WATANABE, W.O.; LOSORDO, T.M.; FITZSIMMONS, K. et al. Tilapia production systems in the Americas: technological advances, trends and challenges. Reviews in Fisheries Science, v.10, n.3, p.465-498, 2002.

WIEGAND, M.D. Composition, accumulation and utilization of yolk lipids in teleost fish. Reviews in Fish Biology and Fisheries, v.6, p.259-286, 1996.

WING-KEONG, N. Potencial of palm oil utilization in aquaculture feeds. Asia Pacific Journal of Clinical Nutrition, v.11, p.473-476, 2002. 